\title{
ARQUITECTURAS EFÍMERAS Y ESCENOGRAFÍAS DE PROPAGANDA FRANQUISTA DURANTE LA GUERRA CIVIL ESPAÑOLA
}

\author{
Amparo Bernal López-SANVicente ${ }^{1}$ \\ Universidad de Burgos
}

\begin{abstract}
En el gobierno provisional de Franco constituido durante la guerra, el Departamento de Plástica del Servicio Nacional de Propaganda congregó a un pequeño equipo de artistas plásticos que tuvieron la oportunidad de liberarse de su destino en el frente para dedicarse a la construcción de la imagen del Nuevo Estado. La Sección de Arquitectura de este departamento se encargaba del diseño de la arquitectura y la escenografía que requerían los actos y ceremonias del gobierno con los que se pretendía mostrar una ciudad dignificada por el nuevo orden social. La arquitectura de propaganda proyectada durante la guerra tuvo carácter efímero y escenográfico, pero en esta etapa también se construyó otra arquitectura de iniciativa castrense, destinada a consolidar el imaginario formal de la arquitectura de propaganda franquista.
\end{abstract}

Palabras clave: arquitectura efímera; escenografía de propaganda; propaganda franquista; guerra civil española.

\section{EPHEMERAL ARCHITECTURE AND SCENOGRAPHIES OF FRANCOIST PROPAGANDA DURING THE SPANISH CIVIL WAR}

In Franco's provisional government established during the war, the Department of Plastic Arts of the National Propaganda Service brought together a small group of plastic artists who had the opportunity of being relieved of military duty in order to create the image of the "New State". The Architecture Section of this department was in charge of designing the architecture and scenography required for the acts and ceremonies of the government in order to show a city dignified by the new social order. This architecture of propaganda designed during the war was ephemeral and a mere stage setting, but likewise during this period another architecture was built under military initiative, aimed at consolidating the formal stereotype of Franco period propaganda architecture.

Key words: ephemeral architecture; propaganda scenography; Franco period propaganda; Spanish Civil War.

Como citar este artículo / Citation: Bernal López-Sanvicente, Amparo (2018): “Arquitecturas efímeras y escenografías de propaganda franquista durante la guerra civil española”. En: Archivo Español de Arte, vol. 91, núm. 362, Madrid, pp. 159-174. https://doi.org/10.3989/aearte 2018.11.

\section{La construcción de un ideario estético de propaganda}

En el primer período del franquismo, desde la creación del gobierno provisional en Burgos en enero de 1938, hasta la primera reorganización del Estado una vez finalizada la guerra en agosto de 1939, se fueron perfilando las directrices que propiciaban la utilización del arte como un instrumento político de propaganda al estilo de los regímenes fascistas de Alemania e Italia.

1 amberlop@ubu.es / ORCID iD: http://orcid.org/0000-0002-2085-8704. 
Un planteamiento que, en España, tenía su referencia ideológica más próxima en el libro de Ernesto Giménez Caballero, Arte y Estado, publicado en 1935.

Con este texto, Giménez Caballero se convirtió en el pionero de los teóricos fascistas preocupados por el arte, ya que en España, como afirma Ángel Llorente, "al contrario de lo que había ocurrido en la izquierda, en la derecha y el fascismo emergente, apenas si se discutió sobre temas artísticos. Ello explica la pobreza teórica y la escasez de escritos sobre el arte de los fascistas españoles" ${ }^{2}$.

Giménez Caballero argumentaba la razón de ser del arte como un arma de combate y como un vehículo de propaganda y didascalia para el pueblo relacionando, de manera forzada, los diferentes aspectos de las artes plásticas con la política, el Estado y la religión católica ${ }^{3}$. Entre todas las artes, señalaba la arquitectura como el arte esencial del Estado y defendía la "necesidad" de la hegemonía de la arquitectura sobre las restantes artes que quedaban supeditadas a su ordenamiento jerárquico.

[...] Estructurar, edificar, ordenar, son los verbos del Estado. Verbos arquitectónicos. Toda resurrección de lo "estatal" en la historia significa un resucitamiento de "lo arquitectónico". Primacía del Estado; primacía de la arquitectura.

[...] Que las otras artes - como falanges funcionales—- se disciplinen y preparen para ocupar su rango de combate y ordenamiento. La Arquitectura tiene el puesto de mando. El Estado. Roma $^{4}$.

Según este ideario falangista, el Nuevo Estado instaurado en España debería contar con un Ministerio de Propaganda que aglutinara todas las artes plásticas, donde la arquitectura tuviera el papel principal ${ }^{5}$. El primer antecedente a este ministerio fue la Sección de Prensa y Propaganda del Movimiento que él mismo fundó en Salamanca en 1936, bajo las órdenes del general José Millán Astray. Posteriormente, en 1937, pasó a denominarse Delegación del Estado para Prensa y Propaganda, dependiente de la Secretaría General del Estado. En 1937, la Junta Técnica del Estado se trasladó a Burgos y empezó a diseñarse la estructura del gobierno provisional de Franco en el cual se separaron las funciones de la delegación precedente en dos servicios dependientes del Ministerio del Interior bajo el mando político de José Serrano Suñer; el Servicio Nacional de Prensa, a cargo de José Antonio Giménez Arnau y el Servicio Nacional de Propaganda, dirigido por Dionisio Ridruejo, donde un escogido grupo de intelectuales, escritores y artistas plásticos conformarían el frente de la propaganda ideológica del Nuevo Estado ${ }^{6}$.

\section{El Departamento de Plástica: un pequeño gueto de artistas}

A partir de febrero de 1938, los recién creados ministerios ocuparon los palacios y edificios públicos de Burgos, transformando la ciudad en la improvisada capital del nuevo gobierno. La vida cotidiana burgalesa adquiría el ajetreo propio de una ciudad administrativa al margen de la guerra que se libraba a tan sólo unos kilómetros de distancia ${ }^{7}$.

\footnotetext{
2 Llorente, 1995: 19.

3 Sobre el arte como didascalia y propaganda, véase: Giménez, 2009: 161.

4 Giménez, 2009: 150-151.

5 Giménez, 2009: 163.

${ }^{6}$ El primer gobierno de Franco instaurado en Burgos quedó definido por ley el 30 de enero de 1938 (BOE 31-I1938). La estructura inicial se mantuvo hasta que la ley de 29 de diciembre de 1938 suprimió el Ministerio de Orden Público pasando sus funciones a Interior que, a partir de ese momento, se denominaría Ministerio de Gobernación con tres Subsecretarías: Interior, Orden Público y Prensa y Propaganda (BOE, 31-XII-1938).

7 Sobre la ocupación de edificios públicos municipales, véase: Archivo Municipal de Burgos (AMBU), exp. AD9401/11, febrero 1938, p. 127 y exp.15-1483. En 1936, Burgos era una ciudad de provincias de unos 40.000 habitantes que al finalizar la guerra, en 1939, había alcanzado una población de 100.000 habitantes sin que se hubieran incremen-
} 
En el Palacio de Justicia, situado en la margen derecha del río Arlanzón, se instalaron el Ministerio de Hacienda y el Ministerio del Interior del cual dependía el Servicio Nacional de Propaganda. Dionisio Ridruejo — que había sido nombrado jefe del servicio el 2 de marzo de $1938^{8}$ - , reunió bajo su mando un amplio y diverso grupo de intelectuales, artistas y profesionales. Entre ellos, los militantes falangistas fueron designados jefes de las diferentes secciones. El resto del equipo se fue formando con amigos y compañeros que, tras haber sido reclamados por su profesionalidad, se incorporaban a los destinos administrativos del recién creado Estado provenientes de los frentes de la guerra9.

El Servicio Nacional de Propaganda comprendía las secciones de Ediciones, Radio, Teatro, Cinematografía, Música y Plástica, donde se agrupaban la pintura, escultura, arquitectura y fotografía. En su autobiografía, Pedro Laín Entralgo, revelaba la estructura del servicio y los nombres de muchos de sus integrantes:

La Sección de Ediciones estaba a mi cargo. A mi lado Antonio Macipe, Rosales, Vivanco, Torrente y poco más tarde Carlos Alonso del Real y Melchor Fernández Almagro. Tovar al frente de la Radio, con Luis Moure Mariño, Cipriano Torre Enciso y Tomás Seseña y otros. En Plástica — la Sección encargada de orientar estéticamente la apariencia del Nuevo Estado-, Juan Cabanas, Manuel Contreras, Pepe Romero Escassi, Pepe Caballero, Pedro Pruna ${ }^{10}$.

El pintor guipuzcoano Juan Cabanas Erausquin fue designado por Dionisio Ridruejo jefe de la Sección de Plástica, también denominada Departamento de Plástica. Juan Cabanas había sido un destacado militante falangista y miembro fundador, junto al arquitecto José Manuel Aizpurua, de la Sociedad Gastronómica Cultural — GU_, creada en San Sebastián en 1934. GU fue el germen político de la Falange Española en la capital donostiarra y el nexo de unión cultural entre la vanguardia europea y el norte de España ${ }^{11}$.

Juan Cabanas formó el grupo inicial de Plástica con Manuel Contreras y los pintores José Romero Escassi, José Caballero y Pedro Pruna que, por entonces, ocupaban su puesto en las filas del ejército del bando sublevado. El destino en Plástica durante la guerra era un salvoconducto para muchos artistas que, habiendo desarrollado sus trayectorias profesionales sin delimitación expresa de fronteras ideológicas, al estallar la guerra se vieron forzados a optar por uno u otro bando ${ }^{12}$. A cambio, debían adoptar las formas y consignas de la propaganda del Régimen en su obra plástica y colaborar en las publicaciones falangistas. Algo que algunos harían por convicción y otros adoptarían por pura supervivencia ${ }^{13}$ (figs.1, 2).

En ese pequeño "gueto" de artistas e intelectuales predominaba el "talante poroso" y la relación "franca y cordial" según lo relata uno de sus afines compañeros ${ }^{14}$. Todos ellos sufrían el

tado sus infraestructuras. Sobre el crecimiento demográfico que soportó la ciudad y las consecuencias económicas, véase: Rilova, 1996: 125-148.

8 BOE, 9-III-1938.

${ }_{9}$ Queda constancia del cambio de destino de varios soldados y falangistas al Servicio de Radio-Propaganda en: Archivo General Militar de Ávila (AGMAV), signatura C.2343, 83,15.

10 En el texto, la relación continúa con los integrantes de las Secciones de Teatro, Cinematografía y una prolija lista de artistas e intelectuales. Laín, 1976: 230.

${ }_{11}$ Entre los integrantes de GU estaban también; Eduardo Lagarde - militar, arquitecto y pintor-, el arquitecto Eduardo Olasagasti y su hermano el pintor Jesús Olasagasti. Véase: López de Sosoaga, 2004: 561-57. A pesar de la estrecha amistad de los tres con Juan Cabanas, ninguno de ellos formó parte del Departamento de Plástica. Entre los legajos del departamento se conservan numerosos dibujos de Lagarde, ya que Juan Cabanas se los había pedido para publicar un libro. Archivo General de la Administración, sección Cultura, Madrid (AGA-C), Caja 21/1475.

12 Se han documentado numerosas carpetas con los portfolios de los artistas que se dirigían a Juan Cabanas para solicitar su ingreso en el Departamento de Plástica. AGA-C, Caja 21/1475, legajos C-56-148.

13 En el ejemplar de abril de la revista Vértice se publicaron dibujos de todos los artistas del recién creado Departamento de Plástica. Véase: Vértice, 9, IV-1938.

14 Además de la referencia autobiográfica de Pedro Laín Entralgo (Laín: 1976: 231), se conservan algunas fotografías del grupo en la Biblioteca Nacional de España. Sala Goya (BNE-G), GC-Caja/74BIS/16, fotografías 16/6; 16/7; 16/8. En cuanto al ambiente cultural, existen evidencias de que se recibían periódicamente revistas alemanas e italianas 


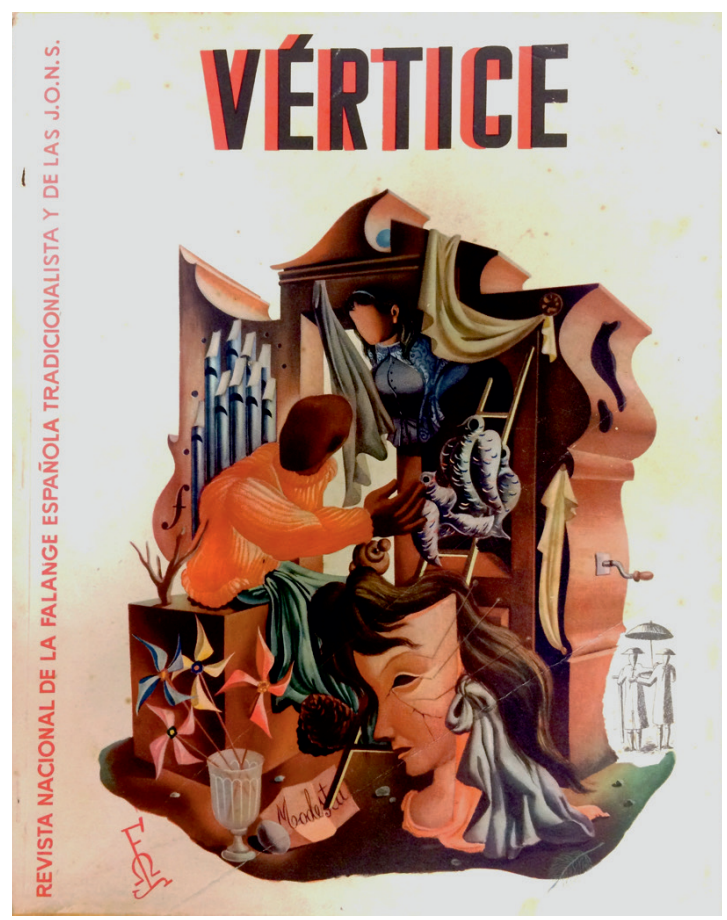

Fig. 1. José Caballero, portada de la revista Vértice, 9, abril 1938.

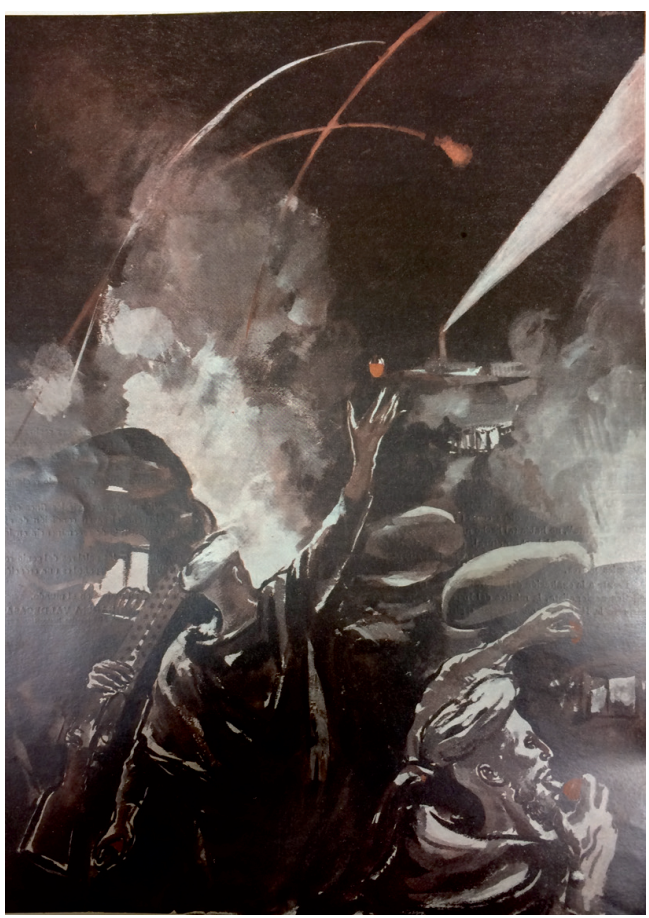

Fig. 2. Pedro Pruna, Ataque nocturno, revista Vértice, 9, abril 1938.

desarraigo de sus vidas precedentes pero, tras liberarse de su misión en la guerra, compartían un mismo destino transitorio dedicándose a su actividad profesional.

Durante 1938 se fueron incorporando al grupo inicial la pintora Margarita Manso, el fotógrafo José Compte y los dibujantes Pedro Rodríguez de la Puente, Cruz López Muller y Pablo Sebastián Cantó ${ }^{15}$. Así, el departamento quedaba estructurado en tres secciones que compartían ubicación en una misma sala del Palacio de la Audiencia de Burgos: dibujo y cartelería, arquitectura y fotografía. El jefe de la Sección de Fotografía fue el fotógrafo catalán José Compte i Argimón que se encargaba de la documentación y la difusión de los actos de propaganda ${ }^{16}$ y en septiembre de 1938, se incorporó al equipo el joven arquitecto zaragozano José Borobio Ojeda como jefe de la Sección de Arquitectura ${ }^{17}$ (fig. 3).

La presencia de un arquitecto en este departamento era excepcional. En la guerra, el destino de los arquitectos era el arma de ingenieros del ejército, porque tanto la Dirección General de Regiones Devastadas, creada en enero de 1938, como el Servicio de Arquitectura de Falange se

de arquitectura; Moderne Bauformen, Baukunst, y Archittetura: rivista del sindacato nazionale fascista architetti, y de diseño gráfico Das Plakat, que se consideraban una referencia imprescindible para los artistas plásticos del Régimen. Oficio del jefe del departamento de plástica al Servicio Nacional de Prensa extranjera, 14 junio 1939, AGA-C, Caja 21/1476, C-56-50.

15 Pedro Rodríguez de la Puente fue el primero en ingresar en Plástica, posteriormente lo harían Cruz López Muller, en julio de 1938 y Pablo Sebastián Cantó en noviembre del mismo año. AGA-C, Caja 21/1477.

16 Existen evidencias del cargo de José Compte i Argimón (Barcelona 1910-1987) como jefe de la Sección de Fotografía en: AGA-C, Caja 21/1615.

17 José Borobio Ojeda (Zaragoza 1907-1984), arquitecto titulado en 1931 en la Escuela Superior de Arquitectura de Madrid. Borobio había estado en Burgos realizando el curso de alférez provisional en la Academia Militar de Ingeniería, al término del cual volvió a incorporarse al frente como teniente provisional del arma de ingenieros. BOE, 01IX-1937: 3140. 
Fig. 3. José

Borobio, sentado a la izquierda junto a otros miembros del Departamento de Plástica. Burgos, noviembre 1938. BNE. Sala Goya, Madrid (BNE-G), GC-Caja/74BIS/16, foto $16 / 6$.

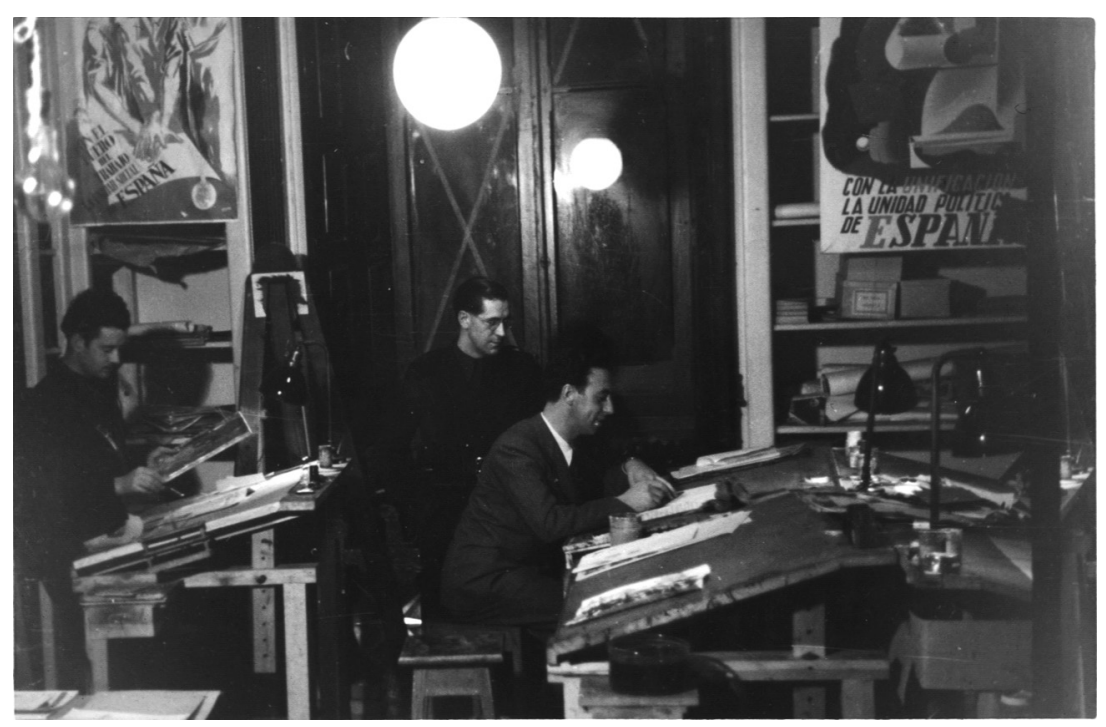

mantuvieron inoperativos hasta el final de la contienda ${ }^{18}$. José Borobio fue reclamado desde Plástica para reforzar el diseño de la arquitectura de propaganda. Hasta ese momento, los proyectos se realizaban bajo las directrices del equipo de pintores y dibujantes, entre los cuales, José Caballero tenía una trayectoria previa de reconocido prestigio en el diseño de escenografías teatrales ${ }^{19}$.

José Borobio, además de su trayectoria profesional como arquitecto, era reconocido por sus extraordinarias dotes de dibujante debido a las asiduas colaboraciones gráficas que mantuvo con revistas humorísticas como Gutierrez y Buen Humor, durante la etapa que vivó en Madrid estudiando arquitectura, entre 1925 y $1931^{20}$. Algunos de los dibujantes y humoristas gráficos de aquellas revistas madrileñas como Antonio Lara de Gavilán — Tono-, Miguel Mihura — Liloy Teodoro Delgado también colaboraban con el Departamento de Plástica a través de las publicaciones falangistas como Vértice y La Ametralladora que se editaban en la Delegación para Prensa y Propaganda de San Sebastián ${ }^{21}$. La relación de José Borobio con muchos de ellos se seguía manteniendo a pesar de las circunstancias de la guerra ya que, a principios de 1938, se publicaron algunos de sus dibujos en el semanario propagandístico La Ametralladora. Así que, posiblemente, esta doble dimensión de José Borobio como arquitecto y dibujante, y su relación previa con los artistas de la vanguardia madrileña fuera determinante para su incorporación al equipo de Plástica22.

18 "Hasta julio de 1939 no empezó a funcionar realmente el Servicio, entre otras razones, porque se quiso esperar a que el licenciamiento militar proporcionara los técnicos y personal competente necesarios [...]". Citado en: Ureña, 1979: 205.

19 Sobre la trayectoria del pintor José Caballero en el diseño de escenografías para teatro, véase: Plaza, 1998 : 95-135.

${ }^{20}$ A cerca de las colaboraciones gráficas de Borobio en las revistas humorísticas, véase: Vázquez, 2000: 411- 460.

21 Tono y Lilo trabajaron antes de la guerra en Buen Humor (1921) y Gutiérrez (1927). Durante la guerra civil, fundaron en San Sebastián el semanario humorístico La Trinchera, editado por la Delegación del Estado para la Prensa y la Propaganda, que a partir del número 4 pasó a titularse La Ametralladora. Semanario de los soldados. Esta revista semanal llegó a publicar 120 números entre el 25-I-1937 y el 21-V-1939. A partir de mayo de 1937, Tono se hizo cargo de la dirección artística de la revista Vértice, que inició su edición en San Sebastián y al finalizar la guerra se trasladó a Madrid donde se editó hasta 1946.

${ }^{22}$ Los dibujos de Borobio se publicaron junto a las viñetas de Troya, Martin y Chuchi en: La Ametralladora, 3001-1938:8. No existe constancia de que Juan Cabanas conociera previamente a José Borobio, ya que fue su hermano 


\section{La arquitectura de la propaganda franquista durante la guerra}

En España, entre 1938 y 1939, debido a las circunstancias de la guerra y a la precariedad económica en la que estaba inmerso el país, no pudieron erigirse monumentos ni construir grandiosos edificios como hicieran Hitler o Mussolini. Sin embargo, siguiendo el ejemplo de los fascismos alemán e italiano, el gobierno franquista, desde su primera estructuración, utilizaría la arquitectura como instrumento político de propaganda destinado a la construcción de la imagen del Nuevo Estado 23 .

La arquitectura de propaganda del gobierno durante la contienda tuvo una doble factura: por una parte, la arquitectura efímera y la escenografía proyectada en el Departamento de Plástica y por otra, la arquitectura funeraria realizada por el ejército.

En el Departamento de Plástica, la Sección de Arquitectura era la encargada de proyectar todo lo relacionado con la arquitectura de propaganda: la organización estética de las celebraciones de masas, los actos públicos y desfiles, la ornamentación de las ciudades, la proyección de monumentos conmemorativos y el diseño de las ferias de muestras y exposiciones ${ }^{24}$.

Esta función confería a la arquitectura un carácter más escenográfico que edificatorio. Los elementos de arquitectura proyectados, además de su condición efímera, se concebían como los hitos configuradores de un espacio, en el cual, los actores - las masas y el ejército- eran los verdaderos protagonistas de las celebraciones de carácter político-religioso-militar. Esta concepción de la arquitectura tenía más que ver con un nuevo arte, tal y como se definía en el artículo sobre "estética de las muchedumbres" publicado en la revista falangista Vértice, que con el arte de proyectar y construir de su raíz etimológica.

Este nuevo arte, que se erigía en la expresión plástica de la fuerza y la unidad del Estado, tenía su máxima expresión en las multitudinarias celebraciones del gobierno. La organización de los actos públicos requería la planificación coordinada de la escenografía arquitectónica y el modelado plástico de las tropas durante la formación y el desfile.

[...] Surge esta estética de modelar efectos con grandes masas de hombres, unidos, enmarcados, sometidos a disciplinas fuertes de buen grado, ilusionados por un ideal de grandeza, apretados contra el peligro, conscientes y solemnes de la expresión plástica de su formación indestructible como cartel contra las falsas teorías demoledoras de pueblos débiles y desunidos [...]. Nace un arte que es coreografía, liturgia religiosa, arquitectura, y poesía a un tiempo. Se crea una estética que busca la expresión de los bloques verticales, el respaldo de monumentos de dimensiones enormes que son como la huella o la planta de una divinidad no olvidada y de un idealismo constante. Se crea un arte, una estética de las muchedumbres que se cuida y se regula como síntesis de toda propaganda ${ }^{25}$.

Por ello, la arquitectura efímera proyectada por el Departamento de Plástica durante la guerra civil no puede considerarse el germen de la arquitectura de la autarquía que posteriormente se realizaría bajo el control de la Dirección General de Arquitectura. La arquitectura de propaganda mantuvo su campo de acción siempre ligado a las necesidades del Servicio Nacional de Propaganda que fue transitando por diferentes ministerios durante los gobiernos del franquismo, sin que sus funciones fueran nunca asumidas por la Dirección General de Arquitectura ${ }^{26}$.

Regino quien había presentado su obra en la exposición que Cabanas y Aizpurua organizaron en San Sebastián, en septiembre de 1930. Véase: "Exposición de arquitectura y pintura modernas en San Sebastián". En: AC, 1931: $14-20,31$.

23 Sobre la utilización de la arquitectura para la transformación de la imagen de la ciudad, véase: Bonet, 1981:36

${ }^{24}$ Las funciones del Departamento de Plástica se describen en un escrito que se conserva en el archivo familiar del arquitecto José Borobio, fechado en Zaragoza el 11 de agosto de 1939. Citado en: Vázquez, 2004: 204.

25 "Estética de las muchedumbres". En: Vértice, 3, VI-1937: 33-36.

26 Terminada la guerra, el 8 de agosto de 1939, se aprobó una nueva ley sobre la Administración Central del Estado (BOE 09-VIII-1939) que modificaba las leyes anteriores de enero y diciembre de 1938. Dentro del Ministerio de la Gobernación se crearon: la Dirección General de Arquitectura dirigida por Pedro Muguruza Otaño (BOE 30-IX-1939), 
Ambas dimensiones de la arquitectura, la propagandística y la edificatoria, se separaron estratégicamente desde la organización del gobierno provisional en Burgos, puesto que paralelamente a la constitución del Departamento de Plástica, se creaba el Servicio Nacional de Regiones Devastadas y se discutían las directrices de actuación de la futura Dirección General de Arquitectura $^{27}$.

La arquitectura de propaganda era necesariamente una arquitectura provisional, desmontable, "de quita y pon" como afirma el historiador Gabriel Ureña ${ }^{28}$. Su objetivo propagandístico era transmitir el mensaje de que el nuevo orden instaurado en el país dignificaría al pueblo y a sus ciudades. Para ello, las fachadas de los edificios se engalanaban con telas y símbolos franquistas y el ámbito urbano donde se desarrollaban los actos quedaba delimitado por distintos elementos arquitectónicos — columnas, banderas y tribunas-, que instalados de forma secuencial, construían el entorno escenográfico que requerían las ceremonias ${ }^{29}$.

La condición tipológica de provisionalidad de la arquitectura de propaganda, lejos de simplificar el diseño arquitectónico, era un importante condicionante en su composición volumétrica que requería la elaboración de una minuciosa planificación del proyecto y su ejecución. Las construcciones se realizaban, al igual que en los decorados teatrales, con estructuras ligeras forradas con paneles de madera que, posteriormente, se revestían con tela, yeso, cartón piedra o pintura. De ahí que en las ocasiones importantes, el proyecto arquitectónico incluyera además la realización de maquetas a escala de los principales elementos ${ }^{30}$.

En los planos también quedaba documentada la zona de afección del desfile en la ciudad y la organización de los accesos de las tropas y las personalidades asistentes al evento. La planificación y puesta en obra de la escenografía arquitectónica se realizaba conjuntamente entre la Sección de Arquitectura del Departamento de Plástica y el ejército ${ }^{31}$. Por ello, cuando los actos no tenían lugar en Burgos, sus responsables debían desplazarse a otras ciudades para dirigir la ejecución material de las obras.

\section{Arquitecturas efímeras y escenografías arquitectónicas entre 1938 y 1939}

Para el estudio detallado de la arquitectura de propaganda franquista en el período del gobierno provisional se han analizado tanto los proyectos ejecutados como aquellos que no llegaron a construirse pero han quedado documentados en los archivos ya que, igualmente constituyen expresiones arquitectónicas imprescindibles para la reconstrucción de este episodio de la historia de la arquitectura moderna en España.

Desde la creación del Departamento de Plástica, en febrero de 1938, se realizaron diversas construcciones para engrandecer los actos públicos organizados por el gobierno con motivo de

la Dirección General de Prensa y la Dirección General de Propaganda de la cual seguiría dependiendo el Departamento de Plástica durante aproximadamente dos años más, hasta que en 1941 todas las competencias se traspasaron al Ministerio de Secretaría General del Movimiento.

27 En febrero de 1938, Pedro Muguruza, jefe de los Servicios de Arquitectura de Falange, congregó en Burgos a un buen número de arquitectos simpatizantes de la causa franquista. En el discurso pronunciado en la Asamblea Nacional de Arquitectos de junio de 1939 se referiría a aquella reunión cuyo principal objetivo había sido la creación de "un ambiente sensible a los problemas por los que atravesaba la arquitectura, y la creación de un cierto sentimiento de unidad que les llevó al convencimiento de que la técnica arquitectónica debía tomar nuevos rumbos y debía participar en las grandes tareas sociales de los nuevos tiempos". Muguruza, 1939: 108.

28 Ureña, 1979: 120.

29 Alexandre Cirici se refiere a la utilización de las artes visuales en el franquismo para ocultar lo conflictivo y transformar la realidad en una imagen de la Unidad, el Orden y la Jerarquía. Cirici, 1977: 24.

${ }^{30}$ Entre los legajos del Departamento de Plástica se conservan facturas de ejecución de maquetas. AGA-C, Caja 21/1476 y Caja 21/1477.

31 Debido a la condición efímera de la arquitectura y a la responsabilidad compartida de su puesta en obra, la documentación que se ha conservado hasta nuestros días es escasa y se halla repartida entre los fondos del Servicio Nacional de Propaganda en el AGMAV, el AGA-C y BNE-G. 

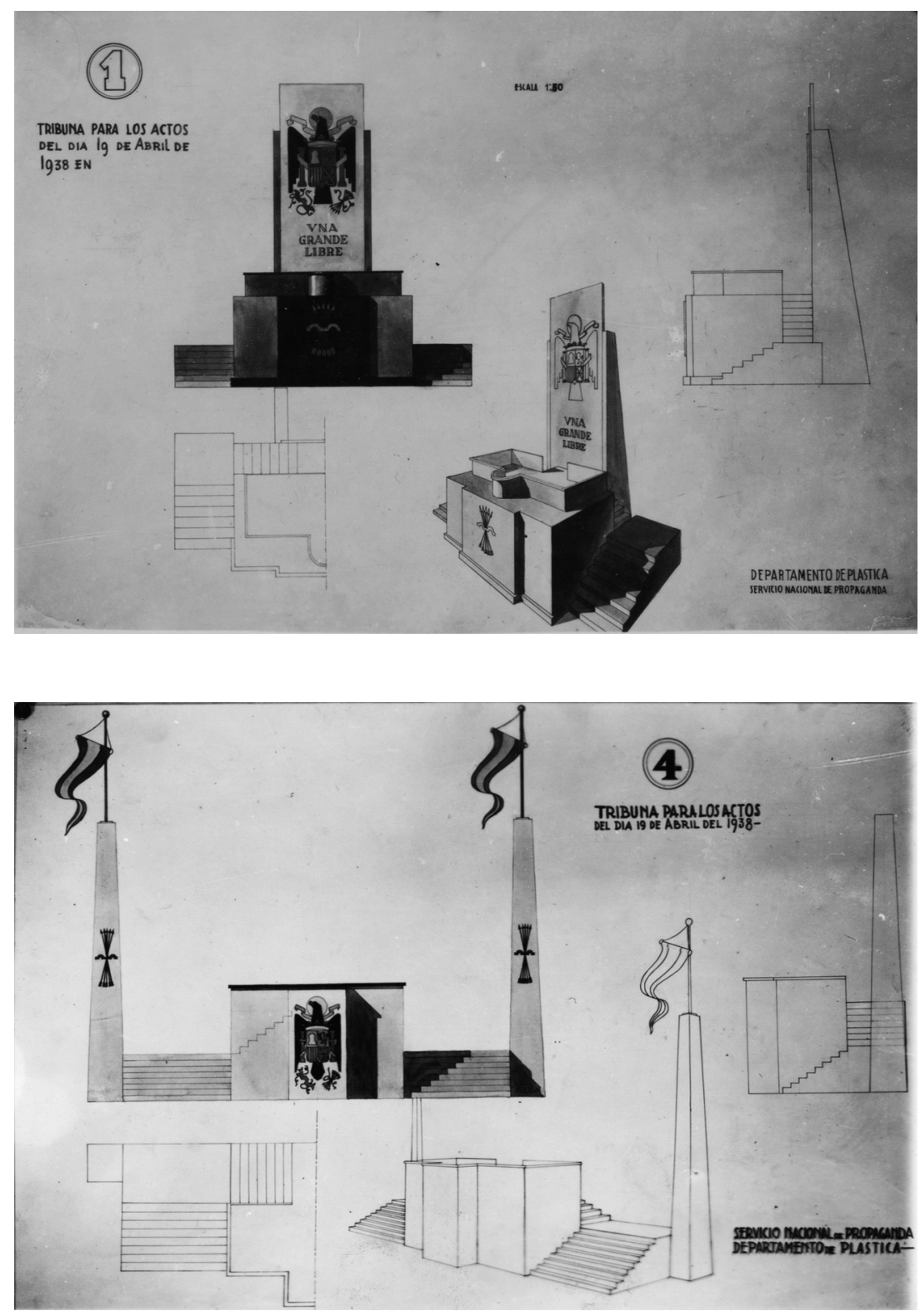

Fig. 4. Tribuna "1" para los actos del 19 de abril 1938. BNE-G, GCCaja/74BIS/18, foto $18 / 10$.
Fig. 5. Tribuna "4" para los actos del 19 de abril 1938. BNE-G, GCCaja/74BIS/18, foto $18 / 11$.

las festividades que había instaurado el nuevo calendario franquista ${ }^{32}$. La incorporación del arquitecto José Borobio marcaría un punto de inflexión en la escala y la tipología de los proyectos, por lo que pueden diferenciarse dos etapas en la arquitectura realizada por este departamento.

\section{Primera etapa: 1938}

La primera etapa se desarrolla desde su creación hasta septiembre de 1938. No existe constancia de que ningún otro arquitecto trabajara en Plástica, dado que Luis Felipe Vivanco siempre

32 La relación y detalles de las fiestas y conmemoraciones del calendario franquista, véase en: Castro, 2008: 194 y Box, 2010: 211-281. 


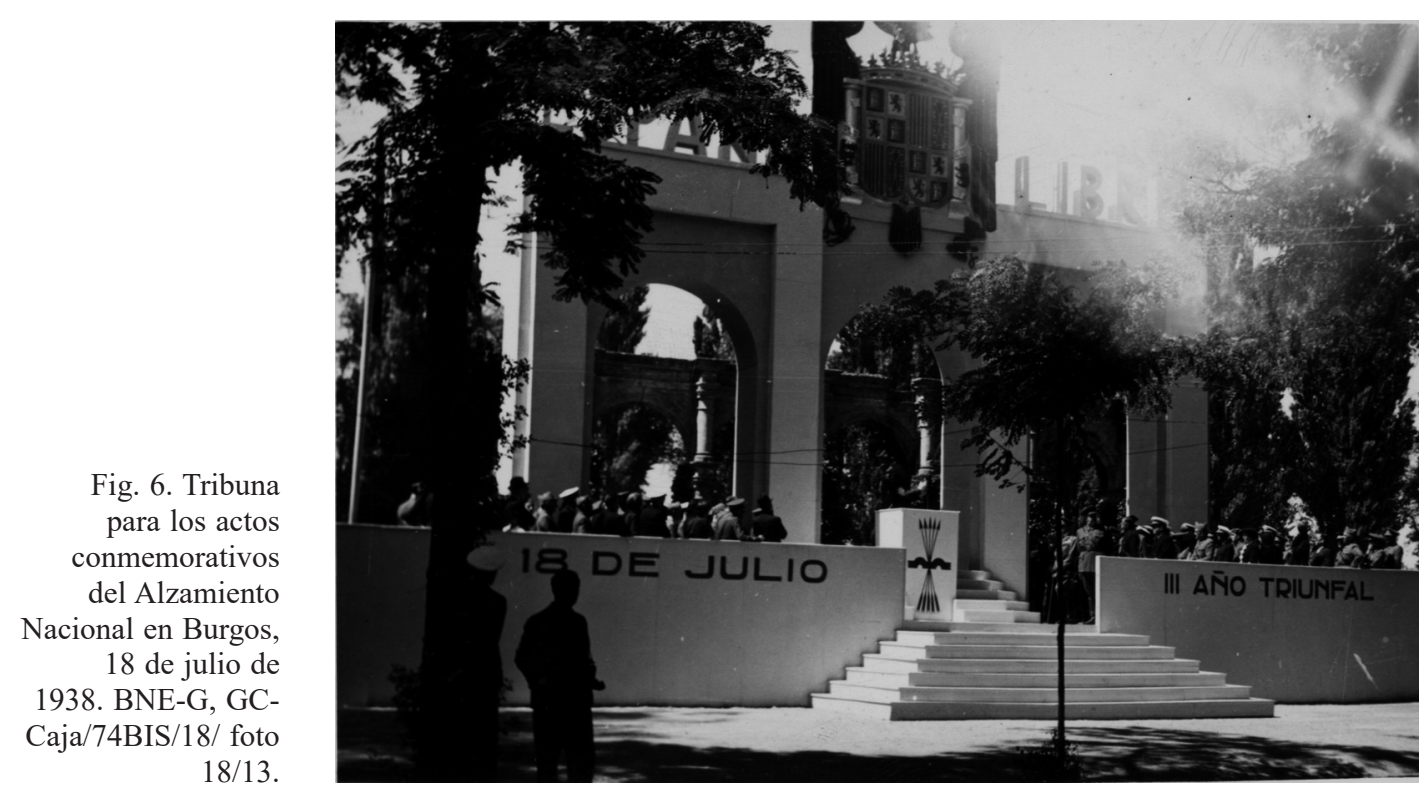

estuvo ligado a la Sección de Ediciones por su trayectoria como escritor y poeta ${ }^{33}$. En este período se realizaron proyectos de elementos aislados de arquitectura efímera con intervenciones de un impacto muy contenido en la ciudad.

Aunque se proyectaron arquitecturas para diferentes ciudades del bando sublevado como Zaragoza o Salamanca, la ciudad de Burgos ofrecía el escenario idóneo para la experimentación. $\mathrm{Su}$ pequeña escala permitía ensayar las formas y construcciones de los primeros proyectos con un presupuesto asumible para la precaria economía del gobierno provisional ${ }^{34}$. En Burgos, los desfiles y otras celebraciones de carácter litúrgico-militar se desarrollaban en los paseos del Espolón y la Isla, en la margen derecha del río Arlanzón, donde estaban situados los palacios y edificios públicos que había ocupado el gobierno.

De esta primera etapa se conservan las fotografías de dos ejemplos de las tribunas realizadas para los actos conmemorativos del 19 de abril en diferentes ciudades ${ }^{35}$. Los planos están identificados con la carátula Departamento de Plástica, pero no están firmados por ningún arquitecto (figs. 4 y 5). A esta misma tipología arquitectónica corresponde también la tribuna instalada en Burgos para el aniversario del Alzamiento Nacional, el 18 de Julio de $1938^{36}$ (fig. 6).

Los primeros proyectos fueron depurando sus composiciones de manera titubeante hasta que los criterios de uniformidad de estilo y de limitación creativa fueron progresivamente instaurándose en el servicio ${ }^{37}$. En ellos se revelan ya las directrices estéticas de la arquitectura de propa-

33 Sobre la pertenencia del arquitecto Luis Felipe Vivanco a la Sección de Ediciones, véase: Laín, 1976:230.

34 Para la instalación del monumento de homenaje a los caídos el 29 de octubre de 1938, el jefe del Servicio Nacional de Propaganda solicitó licencia municipal al ayuntamiento de Burgos y también el sufragio de las mismas. Véase: AMBU, exp. 9-2169.

35 El 19 de abril se conmemoraba el aniversario del decreto de unificación de la Falange Española y Requetés en una sola entidad política. BOE, 20-IV-1937:1033-1034. Una anotación del delineante Pedro Rodríguez de la Puente que se realizaron cuatro proyectos diferentes de tribunas. Véase: Libro de trabajos realizados 1939-1941, AGA-C, Caja 21/1477. Las fotografías de dos planos se conservan en: BNE-G, GC-Caja/74BIS/18, fotografía 18/10 (1); $18 / 11$ (4). Uno de los proyectos de tribuna se instaló en Zaragoza. Véase: “19 de abril. Acto de Zaragoza”. En: Vértice, 10, V-1938.

36 BNE-G, GC-Caja/74BIS/18, fotografía 18/13.

37 A este respecto, cabe señalar que para la celebración litúrgica del 2 de mayo de 1938 se instaló frente al Ayuntamiento de Burgos, en la parte superior del paseo del Espolón, un altar y un obelisco. Posteriormente, en un informe 


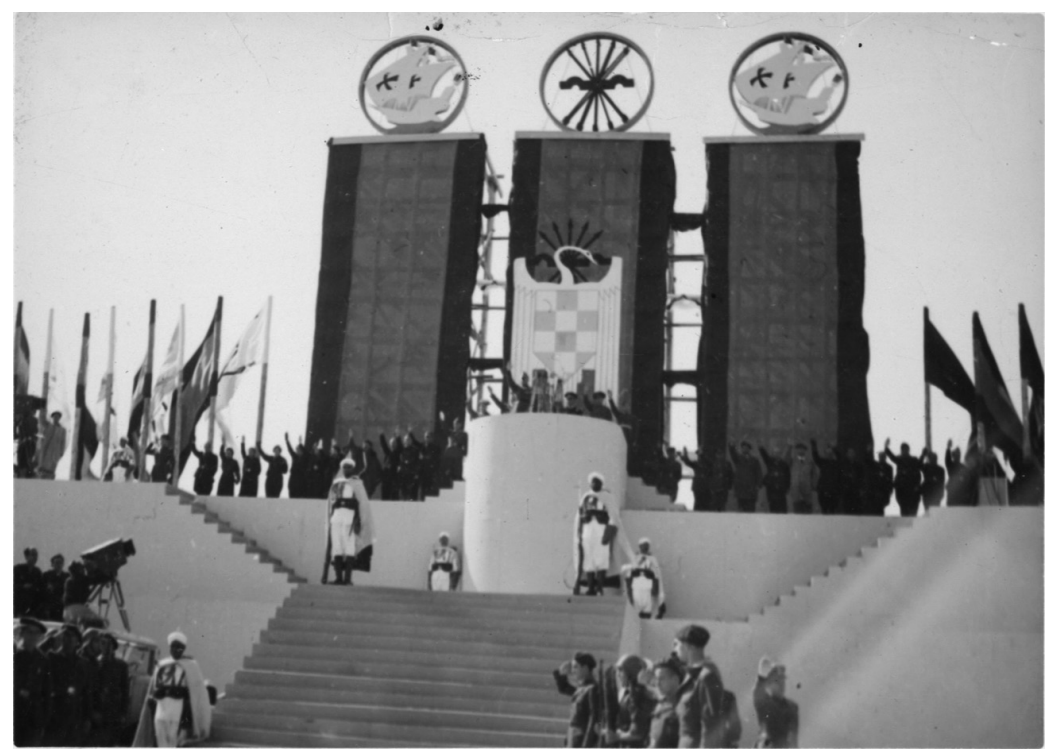

Fig. 7. Tribuna para la celebración del Día de la Raza en Zaragoza, 12 de octubre de 1938. BNE-G, GC-Caja/74BIS/18, foto $18 / 12$.

ganda franquista: composiciones simétricas, formas y volúmenes sencillos, sobrios, rotundos, líneas rectas y acabados austeros con aparente solidez. También aparecen los elementos arquitectónicos que, con un diseño más o menos refinado, se repetirían en todas las escenografías: mástiles y columnas para las banderas, escalinatas, tribunas y estrados.

\section{Segunda etapa: los actos propagandísticos de 1939}

La segunda etapa corresponde a los proyectos desarrollados por José Borobio. A partir de su nombramiento como jefe de la Sección de Arquitectura, la arquitectura de propaganda se hace más compleja. Aún seguirían proyectándose elementos aislados de arquitectura efímera, pero empezaban a gestarse los actos propagandísticos del final de la guerra y el planteamiento de los proyectos fue adquiriendo progresivamente una mayor dimensión escenográfica y urbanística.

Los primeros diseños de Borobio podrían ser el monumento proyectado para la celebración día de la Raza en Zaragoza, el 12 de octubre de $1938^{38}$ y el Monumento a los Caídos instalado en Burgos, el 29 de octubre de $1938^{39}$. Aunque no ha podido documentarse su autoría, ambos proyectos llevaban la impronta de un joven arquitecto comprometido con la modernidad. La composición formal se desmarcaba del academicismo de la arquitectura efímera precedente utilizando las formas curvas y concediendo un mayor énfasis al diseño volumétrico de elementos arquitectónicos, que al eslogan y la decoración simbólica añadida (fig. 7). Pero, a medida que los actos propagandísticos fueron adquiriendo mayor relevancia para el gobierno franquista, la arquitectura fue adoptando un estilo más colosalista y desprendiéndose de la riqueza formal de estos primeros proyectos.

A partir de enero de 1939, cuando las tropas franquistas tomaron Barcelona, empezarían a sucederse los grandes actos propagandísticos de la victoria del ejército sublevado que requerían la intervención directa del Departamento de Plástica. En esta ocasión, José Borobio y el fotógra-

firmado por el jefe del Departamento de Plástica, de fecha 3-8-1938, Juan Cabanas calificaba al obelisco como un "símbolo pagano de la muerte", "que no encierra en él ninguna idea de Redención, de Sacrificio ni de Vida Eterna". Citado en: Llorente, 1995: 280. Las fotografías del acto se conservan en: BNE-G, GC-Caja/74/14.

38 BNE-G, GC-Caja/74BIS/18, fotografía 18/12

39 Las fotografías del monumento están en: BNE-G, GC-Caja/74/3, fotografías 3/6; 3/7; 3/8. 
fo José Compte se desplazaron a la ciudad condal para diseñar, organizar y documentar las celebraciones que presidiría el jefe del Estado, el 21 de febrero de $1939^{40}$.

Los actos se concibieron inicialmente con una ambición desmesurada que sobrepasaba la escala que hasta ese momento se había tanteado en Burgos. El desfile por las calles de Barcelona anticipaba el escenario de una victoria definitiva para el ejército de Franco y el Servicio Nacional de Propaganda intentaba rentabilizar al máximo su efecto propagandístico. Durante el tiempo que Borobio permaneció en Barcelona se esbozaron las propuestas arquitectónicas con las que se pretendía transformar el paseo de Gracia y la plaza de Cataluña en un gran escenario jalonado de monumentos, columnas e hiladas de monolitos coronados por la bandera. Además, el diseño escenográfico incluía la decoración de las fachadas con mapas de España que expresaban gráficamente el avance de las tropas de Franco desde la sublevación militar en julio de 1936 hasta la situación en febrero de $1939^{41}$.

La escala de los monumentos proyectados eclipsaba las intervenciones realizadas anteriormente y alcanzaba dimensiones inusitadas para el género de la arquitectura efímera ${ }^{42}$. Pero, a pesar de la rentabilidad propagandística que habrían tenido estas obras, el gobierno no podía eludir la situación de precariedad en la que se encontraba la ciudad de Barcelona cuando entraron las tropas. Así que, la escasez de recursos económicos y materiales dejaría en esbozos uno de los proyectos de escenografía propagandística más espectaculares del franquismo que, finalmente, prescindiendo del ambicioso planteamiento inicial, se limitó al desfile triunfal de las tropas y la exhibición de los medios logísticos del ejército ${ }^{43}$.

En todo caso, la organización militar de este acontecimiento sirvió de ensayo para los desfiles que se sucedieron, una vez finalizada la guerra, en Sevilla, Valencia y, por último, en Madrid, el 19 de mayo de 1939. Con la experiencia de la ciudad condal, los actos conmemorativos de la Victoria se concibieron como impresionantes paradas militares y el diseño arquitectónico y escenográfico se reservó para el desfile de Madrid ${ }^{44}$.

Poco después del regreso de la delegación de Barcelona a Burgos, un nuevo equipo formado por José Borobio, Cruz López Muller y Pedro Rodríguez de la Puente se trasladaron a Madrid para dedicarse al proyecto y a la supervisión de las obras del desfile, donde trabajarían coordinadamente con el ejército y un pequeño grupo de colaboradores ${ }^{45}$.

Los actos conmemorativos de la capital comenzaron el 12 de mayo con la revista a las fuerzas aéreas en el aeródromo de Barajas. Este evento tenía un carácter más castrense que propagandístico, puesto que la asistencia de público estaba muy limitada. No se proyectaron tribunas para contemplar el desfile. Las autoridades, tanto civiles como militares, y el escaso público asistente se ubicaron en las terrazas y pasarelas del desaparecido edificio expresionista realizado por Luis Gutierrez Soto desde donde presidiría el desfile el jefe del Estado ${ }^{46}$.

40 José Borobio se fue a Barcelona el 21 de enero de 1939 y permaneció allí hasta finales de marzo. "Plan del Departamento de Plástica. Ocupación de Barcelona". AGA-C, Caja 21/1477, Proyectos de Entrada de tropas, C56-56. Las fotografías tomadas por José Compte se publicaron en: "Gran Desfile". En: Vértice, 20, IV-1939.

${ }^{41}$ Se han documentado catorce planos entre bocetos, dibujos acotados y perspectivas que no alcanzan la definición gráfica de un proyecto y no están firmados, aunque en el reverso de uno de ellos figura el membrete del estudio de José Borobio. Véase: Libración de Barcelona. AGA-C, Caja 21/1476.

42 Sobre el colosalismo en el arte del franquismo, véase: Cirici, 1977: 31.

43 "Apoteosis de España y del ejército en la persona del Generalísimo, aclamado con entusiasmo inefable en Barcelona". En: $A B C$, Sevilla, 22-II-1939:7-8.

${ }^{44}$ No existen pruebas documentales de que la Sección de Arquitectura participara en los actos de Sevilla y Valencia. Del desfile de la Victoria en Valencia realizado en el paseo de la Alameda, el 3 de mayo de 1939, se conservan las invitaciones y los croquis detallando el orden de las divisiones en el desfile y de la ubicación de las tribunas. AGMAV. C.2537, 29; M 2143,12.

45 Desde su llegada a Madrid, el 15 de abril de 1939, trabajarían junto a: Domingo Viladomat Pancorbo, Javier Conde García, José Solas, Guillermo Reina, Amelia Vera García, Anita Sáez de Sicilia Benavides y Pilar Gaspar AlorOú. Véase: Oficio del jefe del Departamento de Plástica, 28 de junio de 1939, AGA-C, Caja 21/1477.

46 Se han documentado algunos planos con la ubicación de los aviones, la disposición de las tropas para la revista y el desfile, los accesos y recorridos de las autoridades, pero no tienen la definición de proyecto ni están firmados. AGMAV, signatura C.2535,5; M.2143,138; M.2143,14 y M.2143,15. 

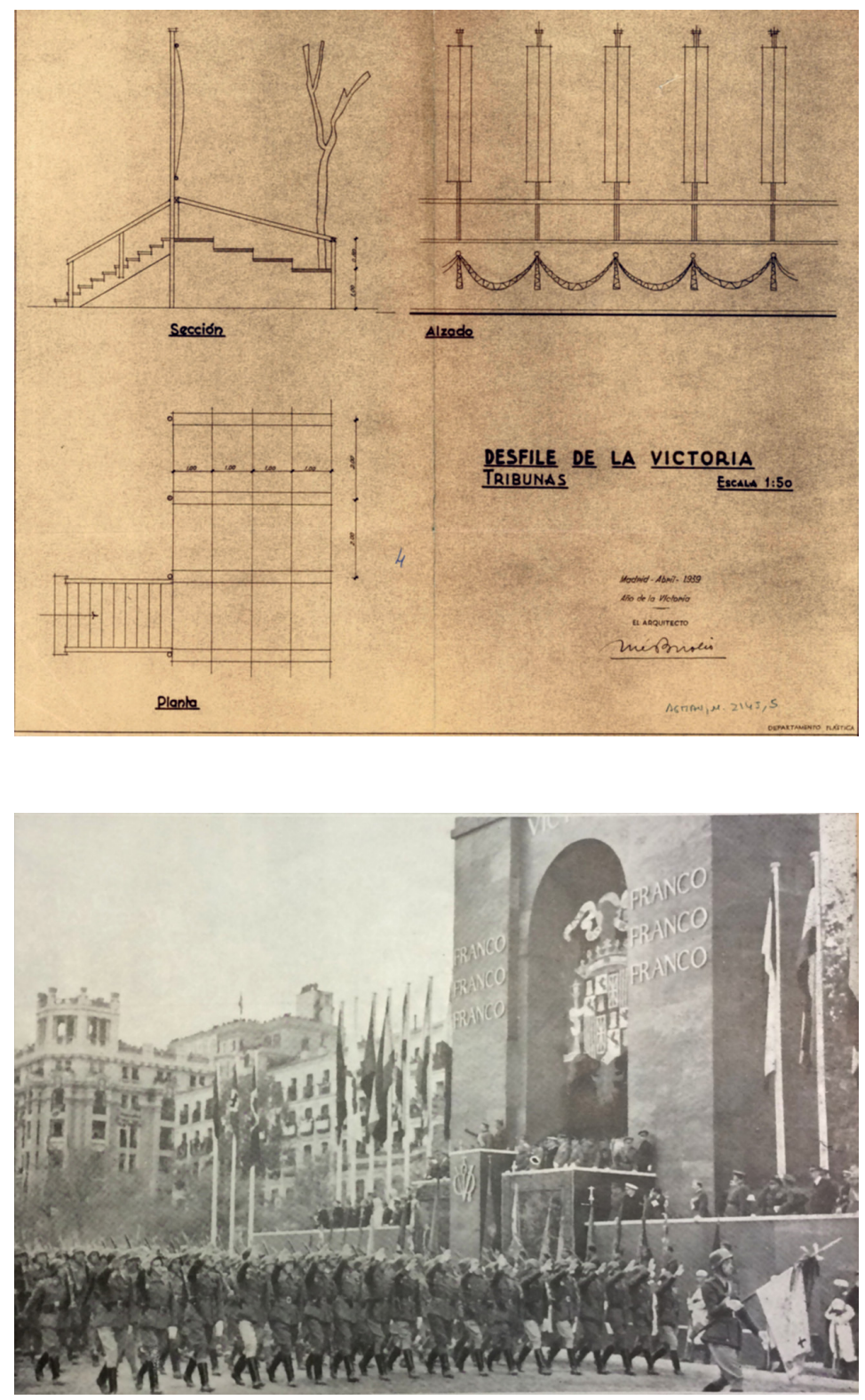

Fig. 8. José Borobio. Plano de las tribunas del desfile de la Victoria, Madrid, 19 de mayo de 1939. (AGMAV), M.2145, 5.

Fig. 9. Tribuna principal del desfile de la Victoria en Madrid, 19 de mayo de 1939. Revista Vértice, 22, mayo 1939.

El objetivo principal de la delegación de Plástica era el diseño del gran acto de exaltación del Caudillo y de su Victoria del 19 de mayo en Madrid $^{47}$. Se trataba del proyecto más importante del Servicio Nacional de Propaganda por lo que la escenografía no podía improvisarse, ni reutilizar elementos arquitectónicos ensayados en otras celebraciones. La envergadura de las obras tan solo podría haberse asimilado a la experiencia del frustrado proyecto de la liberación de Barcelona que no había llegado a construirse.

José Borobio diseñó una serie de elementos arquitectónicos; pilonos, tribunas, mástiles con banderas y guirnaldas que, dispuestos a lo largo del recorrido por el paseo de la Castellana-Re-

47 Véase: Detalle para los trabajos a realizar por el Departamento de Plástica para el Plan de Propaganda de entrada en Madrid, AGA-C, Caja 21/1477, Proyectos de entrada de tropas, C56-56. 
coletos-Prado, conformarían la secuencia escenográfica del desfile ${ }^{48}$. Las torres-pilonos eran los elementos más singulares. Se trataba de unas esbeltas estructuras efímeras con planta en forma de hache en cuyos los laterales se grabaron los nombres de las ciudades tomadas por el ejército de Franco y de sus batallas más significativas.

Se colocaron marcando un ritmo binario a ambos lados del inicio del recorrido en la plaza del monumento a Emilio Castelar. Durante el trayecto, una torre a cada lado señalaba el ligero quiebro hacia el tramo donde se situaban las tribunas, entre las calles Lista - actualmente Ortega y Gasset- y Marqués de Villamagna.

La tribuna principal destacaba, por su escala y diseño, del resto de tribunas de las autoridades civiles y militares que se situaban enfrente y junto a ella (fig. 8). En el basamento se yuxtaponían de forma ascendente los volúmenes de los estrados destinados al gobierno y autoridades militares, destacando en la zona central el podio reservado para el Caudillo. En la parte posterior, un impresionante arco de triunfo dignificaba el centro de la composición ${ }^{49}$ (fig. 9).

La depuración formal de la arquitectura de propaganda había encontrado en estos elementos arquitectónicos de líneas verticales, composiciones clasicistas, simétricas, de volúmenes sencillos, rotundos y austeros, la expresión canónica de los valores del Nuevo Estado. El arco de triunfo se adoptaría como elemento simbólico en la arquitectura monumental de la autarquía y en la arquitectura de propaganda se repetiría en los sucesivos desfiles de la Victoria, aunque con significativas variaciones en el diseño formal y la escala ${ }^{50}$.

\section{Otras arquitecturas oficiales: los monumentos funerarios}

Durante la guerra, coincidiendo con el período de mayor actividad arquitectónica del Departamento de Plástica, se desarrolló otra arquitectura oficial, proyectada y construida directamente por el ejército, que quedó documentada por la Sección de Fotografía de propaganda. Se trata de los monumentos funerarios al general Mola y a los Caídos de la 62 división, construidos durante los primeros meses de 1939. En ambos casos, la iniciativa política y castrense de su construcción anulaba los trámites necesarios para su aprobación, ya que los monumentos oficiales se consideraban la expresión canónica de los valores plásticos que se identificaban con el espíritu del Movimiento y por tanto quedaban exentos de la censuras ${ }^{51}$.

La inauguración del monumento a Mola compartió protagonismo en la revista Vértice con el desfile de la Victoria en Madrid como actuaciones paralelas de la estrategia de propaganda franquista que, en el primer caso, ensalzaba el populismo de los actos conmemorativos de la Victoria $y$, en el segundo, reforzaba la necesidad de homenajear a sus víctimas ${ }^{52}$.

El monumento a Mola se construyó en el mismo lugar donde se había estrellado la avioneta en la que viajaba el general junto a otros cuatro militares, en junio de 1937. Un abrupto paraje denominado el cerro del Perejil, situado en el término municipal de Alcocero de Mola, a unos 35

\footnotetext{
48 Sobre el recorrido del desfile y el orden de las fuerzas militares, véase: "La orden general del ejército del centro". En: $A B C$, Madrid, 18-V-1939:11-13.

49 El proyecto de José Borobio se conserva en: AGMAV, signaturas M.2143,3 (Tribuna para el Caudillo. E: 1/100); M.2143, 4 (Pilonos de entrada a la Castellana. E: 1/100); M.2143, 4 (Esquema de situación de elementos decorativos. E: 1/2000); M.2143,5 y M.2143,6 (Detalle de elementos tipo A y B); M.2145,5 (Tribunas. E: 1/50). La documentación técnica del proyecto no detallaba la ubicación de los tapices y pendones que, junto a la decoración de los locales comerciales y fachadas, reforzarían el valor propagandístico del evento, véase: "Las históricas enseñas". En: $A B C$, Madrid, 20-V-1939: 11.

50 Véase los arcos de triunfo de los desfiles de 1940 y 1941: “En el primer aniversario de la paz". En: Vértice, 30-31, III-IV-1940; "Segundo aniversario de la Victoria". En: Vértice, 43, III- 1941.

${ }^{51}$ En otros casos contemporáneos de iniciativa municipal en los que se pidió autorización para la realización de monumentos a los caídos quedaron en suspenso en tanto no se ordenaran las directrices de un plan general de conmemoración y de Monumentos a los Caídos. Véase: Llorente, 1995: 276.

52 Véase: "Desfile de la Victoria" e "Inauguración del monumento al general Mola". En: Vértice, 22, V-1939.
} 


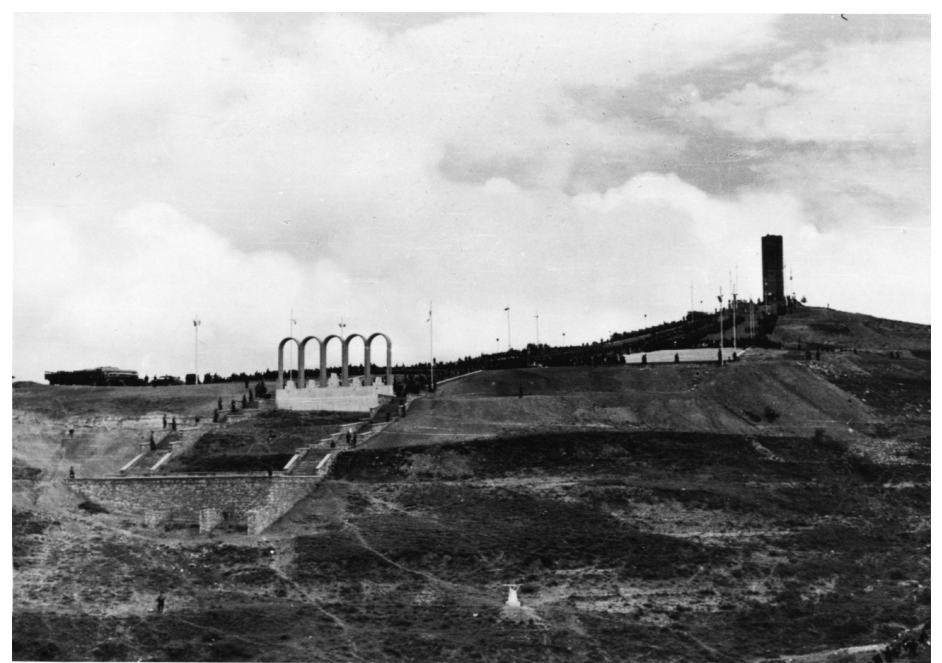

Fig. 10. Vista del conjunto arquitectónico de Alcocero de Mola, Burgos, 1939. 10. BNE-G, GC-Caja/74BIS/18/, foto $18 / 6$.

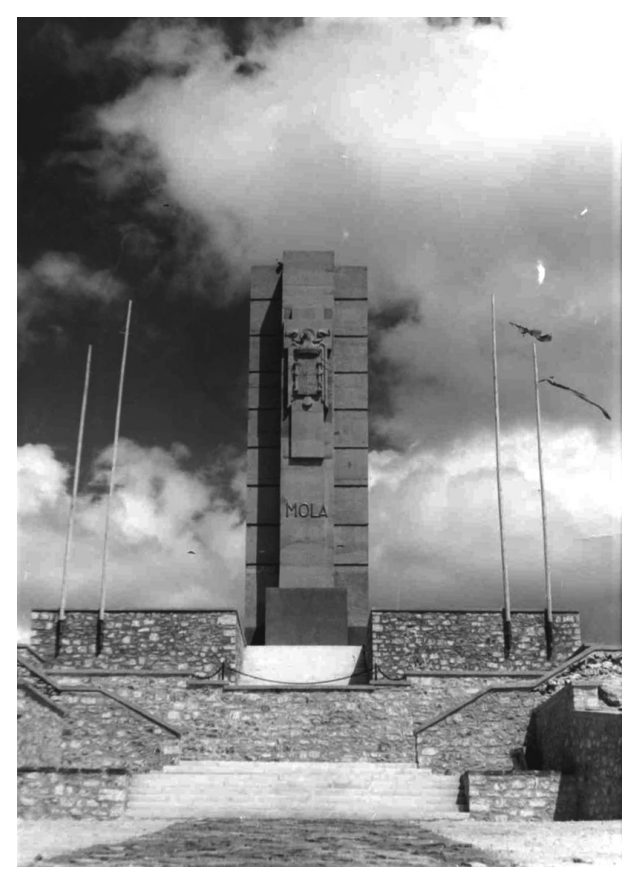

Fig. 11. Monumento a Mola, Alcocero de Mola, Burgos. (ADPBU). Fondo PH-42007 kilómetros de Burgos. Poco después del accidente se iniciaron los trabajos para erigir un monumento en su memoria siguiendo las directrices del proyecto del coronel de ingenieros Joaquín Coll destinado en la Comandancia de Obras de la VI región militar ${ }^{53}$.

El conjunto arquitectónico fue concebido como un impresionante escenario al aire libre al estilo de las escenografías creadas por el Tercer Reich. Situado en la ladera de la montaña, ocupaba una franja de unos 300 metros de longitud con un desnivel de 50 metros desde el recinto del camposanto hasta la explanada superior donde se situaba la torre de piedra. A ambos lados del eje visual principal se disponía el graderío de piedra ocupando una anchura máxima de 50 metros. El diseño tenía todos los elementos formales de la arquitectura de propaganda franquista acentuados por la austeridad del lugar y la elocuencia ascética de la pendiente ascendente del cerro (fig. 10).

La crónica de la revista falangista, a diferencia de la prensa nacional, pasaba por alto la descripción arquitectónica, centrándose exclusivamente en la emotividad del homenaje $\mathrm{e}^{54}$. Las fotografías del reportaje tampoco evidenciaban la magnitud de las obras ejecutadas, ya que la escenografía de la ceremonia no resultaba diferente a las instalaciones efímeras realizadas por el Departamento de Plástica en los actos del gobierno. Sin embargo, actualmente, por tratarse de una obra perdurable, se ha convertido un ejemplo paradigmático de la escenografía arquitectónica franquista realizada durante la guerra (fig.11).

${ }^{53}$ En el dorso de las fotografías que se conservan entre los legajos del Departamento de Plástica se atribuye la autoría del proyecto al coronel de Ingenieros Joaquín Coll. BNE-G, GC-Caja /74BIS, fotografías /18/6 (vista del conjunto); 18/3 (maqueta); 18/8 (inauguración).

${ }^{54}$ Véase la descripción arquitectónica en: "La inauguración del monumento al general Mola". En: $A B C$, Madrid, 04-VI-1939:01-10 
El otro ejemplo de arquitectura de propaganda construida es el monumento a los Caídos de la 62 división situado en el páramo de Bricia, en la provincia de Burgos. Su construcción cumplía la promesa realizada por el general de la división Antonio Ramos Sagardía a sus soldados. El proyecto fue realizado por uno de ellos, el arquitecto donostiarra integrante del grupo GU, Eduardo Olasagasti, y construido por el arquitecto José Antonio Olano al mando de las compañías del $6{ }^{a}$ batallón de zapadores minadores ${ }^{55}$.

El diseño arquitectónico del monumento no se ajustaba a la estética de austeridad formal adoptada por la arquitectura de propaganda y tampoco incluía la cruz como elemento destacado. Se trataba de un volumen poliédrico, de diseño rotundo, formado por caras triangulares que suavizaban los ángulos y aristas con formas ligeramente curvadas e inclinadas respecto a la vertical. La composición volumétrica era compleja y estaba llena de matices que suscitaban diferentes interpretaciones según la perspectiva visual. Todo lo contrario a la impuesta uniformidad y simplicidad formal defendida por la propaganda del Régimen. Por ello, en este caso, la iniciativa castrense sería el salvoconducto necesario para concederle el beneplácito de la crítica falangista, que lo calificaba de "rara belleza arquitectónica"56 (fig.12).

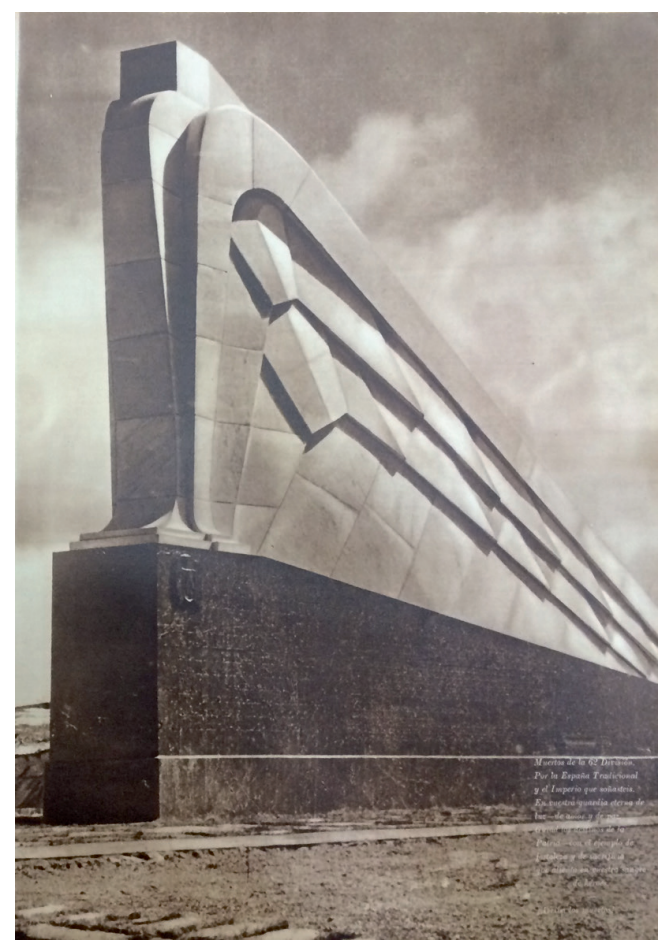

Fig. 12. Monumento a los Caídos de la 62 división, Cilleruelo de Bricia, Burgos, 1939. Revista Vértice 30-31, Marzo-Abril 1940.

\section{Final de una etapa. Disolución del Departamento de Plástica en Burgos}

La organización del desfile de la Victoria en Madrid fue el último proyecto del Departamento de Plástica de Burgos. Los continuos desplazamientos de sus miembros a otras ciudades fueron disgregando el equipo y afectando a su capacidad operativa ${ }^{57}$. Después de que José Borobio y dos delineantes se trasladaran a Madrid, en abril de 1939, la actividad plástica de propaganda en Burgos se vio seriamente afectada en favor de la producción que empezaba a desarrollarse en la capital que, paulatinamente, iba retomando su protagonismo $0^{58}$.

Durante la primera quincena del mes de julio, cuando todavía permanecían en la capital José Borobio y Pedro Rodríguez de la Puente, su equipo de colaboradores en Madrid recibió el encar-

55 Sobre la promesa del general y la autoría del proyecto, véase: Ramos, 1940:19 y Expediente del monumento conmemorativo de la 62 división en Cilleruelo de Bricia, Archivo Diputación Provincial de Burgos (ADPBU), signatura 657/37. No se publicó la inauguración oficial del monumento que ya estaba terminado cuando el conde Galeazzo Ciano hizo su ofrenda ante el monumento durante su visita a España. Véase: "El conde Ciano en España". En: $A B C$, Madrid, 15-VII-1939: 05-07.

${ }^{56}$ La crítica arquitectónica del monumento se publicó un año después. "Monumento a los caídos". En: Vértice, 30-31, III-IV-1940.

57 Al finalizar la guerra, el Departamento de Plástica que estaba integrado por: Juan Cabanas, el secretario, los jefes de las tres secciones; cartelería y dibujo, arquitectura y fotografía, ocho dibujantes, dos ayudantes de dibujante, una encargada del archivo fotográfico y una mecanógrafa. Oficio del jefe del Departamento de Plástica al Secretario General, 19 de abril de 1939, AGA-C, Caja 21/1477.

58 Pocos días después, Juan Cabanas solicitaba la incorporación de un delineante para la realización de trabajos de rotulación. Oficio del jefe del Departamento de Plástica, 20 de abril de 1939, AGA-C, Caja 21/1476. 
go de diseñar y planificar los actos para recibir al ministro de Relaciones Exteriores italiano, el conde Galeazzo Ciano. Debido a la envergadura del encargo, tuvieron que incorporarse a este trabajo José Caballero y José Romero Escassi, lo cual sería el detonante definitivo para la desaparición de la sede burgalesa y la creación de una delegación de Plástica en la capital ${ }^{59}$.

A finales del verano, empezaron a ponerse en marcha los cambios estructurales del primer gobierno de Franco definido el 9 de agosto de 1939. La jefatura del Estado todavía permanecería en Burgos hasta finales de octubre, pero desde principios de septiembre, la delegación de Madrid se había convertido ya, de hecho, en la sede definitiva del Departamento de Plástica ${ }^{60}$.

En cuanto a la Sección de Arquitectura, José Borobio se había trasladado a Zaragoza en el mes de julio con motivo de su permiso estival. Allí se incorporó al trabajo en el estudio de su hermano Regino Borobio y, aunque todavía se mantendría vinculado al departamento hasta finales de año, ya no volvería a incorporarse a su nueva sede en la capital ${ }^{61}$. En Madrid, una vez finalizada la guerra, la arquitectura de propaganda franquista había iniciado una nueva etapa.

\section{BIBLIOGRAFÍA}

Bonet Correa, Antonio (1981): "Espacios arquitectónicos para un nuevo orden”. En: Bonet Correa, Antonio (ed.) (1981): Arte del franquismo. Madrid: Cátedra, pp. 11-46.

Box, Zira (2010): España, año cero: la construcción simbólica del franquismo. Madrid: Alianza.

Castro, Luis (2008): "El recuerdo de los caídos: una memoria hemipléjica". En: Ebre 38. Revista internacional de la Guerra Civil (1936-1939), 3, pp. 163-197.

Cirici, Alexandre (1977): La estética del franquismo. Barcelona: Gustavo Gili.

Giménez Caballero, Ernesto (2009): Arte y Estado. Madrid: Biblioteca Nueva.

Laín Entralgo, Pedro (1976): Descargo de conciencia (1930-1960). Barcelona: Barral.

Llorente Hernández, Ángel (1995): Arte e ideología en el franquismo (1936-1951). Madrid: Visor.

López de Sosoaga, M. Jesús (2004): “Jesús Olasagasti, animador del protagonismo cultural que tuvo San Sebastián antes de la Guerra Civil”. En: Ondare, cuadernos de artes plásticas y monumentales, 23, pp. 561-573.

Muguruza, Pedro (1939): "Ideas generales sobre Ordenación y Reconstrucción Nacional”. En: Texto de las sesiones celebradas en el Teatro Español de Madrid por la Asamblea Nacional de arquitectos los días 26, 27 y 28 de junio de 1939. Madrid: Servicios Técnicos de FET y de las JONS, Sección de Arquitectura.

Plaza Chillón, José Luis (1998): “Tendencias de la escenografía teatral en España de 1920 a 1936 entre la tradición y la vanguardia: De Salvador Alarma a Maruja Mallo”. En: Teatro: Revista de Estudios Culturales / A Journal of Cultural Studies, 13-14, pp. 95-135.

Ramos Sagardía, Antonio (1940): Del Alto Ebro a las fuentes del Llobregat: treinta y dos meses de guerra de la 62 división. Madrid: Editora Nacional.

Rilova Pérez, Isaac (1996): "Burgos durante la Guerra Civil Española (1936-1939): el año 1936”. En: Boletín de la Institución Fernán González, 212, pp. 125-148.

Ureña, Gabriel (1979): Arquitectura y urbanistica civil y militar en el periodo de la autarquía (1936-1945). Madrid: Istmo.

Vázquez Astorga, Mónica (2000): “José Borobio y el dibujo humorístico”. En: Artigrama, 15, pp. 411-460.

Vázquez Astorga, Mónica (2004): “Celebraciones de masas con significado político: los ceremoniales proyectados desde el departamento de plástica en los años de la guerra civil española”. En: Artigrama, 19, pp. 197-226.

Fecha de recepción: 20-XII-2016

Fecha de aceptación: 14-VI-2017

59 Alegando la entidad de los trabajos realizados para la decoración de Madrid con motivo de la llegada del ministro de Relaciones Exteriores de Italia, el Conde Ciano el 15 de julio de 1939, se solicitaba al jefe del Departamento de Plástica una representación del departamento en Madrid. En aquel momento trabajaban en Madrid, José Romero Escassi y José Caballero junto a Domingo Viladomat y los auxiliares Ángel del Castillo y Francisco Verdú. Informe al Jefe Nacional del Departamento de Plástica, 8 julio de 1939, AGA-C, Caja 21/1477.

${ }^{60}$ A partir de septiembre de 1939, los escritos del jefe del Departamento de Plástica están registrados en Madrid. AGA-C, Caja 21/1476, legajos C-56-56.

61 Juan Cabanas autorizó a José Borobio a permanecer en Zaragoza para supervisar las obras del proyecto de Hospedería del Pilar y del Palacio de Exposiciones que se inaugurarían en el centenario de la Virgen del Pilar. Oficio del Jefe del Departamento de Plástica, 8 de agosto de 1939, AGA-C, Caja 21/1477. 